\title{
La Iglesia católica en el altiplano: cinco décadas de trabajo pastoral en la prelatura de Ayaviri (1959-2005)
}

\author{
Alejandro Estenós Loayza \\ Manuel Ugarte Cornejo
}

\section{RESUMEN}

Basándose en fuentes documentales diocesanas, el presente estudio propone y desarrolla una periodificación de cuatro etapas en el trabajo pastoral de la prelatura de Ayaviri, una importante jurisdicción eclesiástica en el sur andino peruano. Las fases determinadas en un período de casi 50 años son las siguientes: 1) tradicional-conservadora (1959-1969), 2) indigenista-culturalista (1970-1974), 3) político-liberacionista (1975-1992) y 4) político-democratizadora (1993-2005). 
En estas etapas se muestran importantes cambios en los diversos enfoques pastorales y sus implicancias en la acción de la Iglesia en los aspectos religioso — sacramentales, litúrgicos y catequéticos o del culto popular-y político-social.

Palabras Clave: Pastoral católica, indigenismo, culturalismo, Teología de la Liberación, democracia en la Iglesia, religión andina.

\section{Abstract}

Based on ecclesiastical primary sources, this paper proposes a sequence of four historical stages of pastoral practice in the Prelature of Ayaviri, an important diocese in the southern Andes of Peru. The determinate phases in a period of almost fifty years are: 1) traditional-conservative (1959-1969); 2) indigenous-cultural (1970-1974); 3) politicalliberationist (1975-1992); and 4) political-democratizing (1993-2005). This analysis points out important changes in pastoral efforts and their implications for the Church's work in religious (sacramental, liturgical, catechismal or popular religious practices) and social-political terms.

KEY worDs: Catholic pastoral, Indigenism, Culturalism, Theology of Liberation, democracy in the Church, Andean religion.

\section{INTRODUCCIÓN}

LA PRESENCIA DE LA IGLESIA CATÓLICA en la llamada región surandina del Perú se remonta a los albores del siglo XVI, en el contexto 
de la conquista político-militar del imperio de los incas y de un significativo despliegue evangelizador que posteriormente, según Manuel Marzal (1982), lograría cristianizar en su mayoría a la población indígena. Esta región — considerada desde sus inicios tierra de misión - perteneció eclesiásticamente primero a la arquidiócesis del Cusco y luego a la diócesis de Puno, que había sido creada por el papa Pío Ix el 9 de octubre de 1861, fraccionando territorios de las diócesis del Cusco y de La Paz. Finalmente, en la segunda mitad del siglo xx, el papa Pío XII creó prelaturas territoriales en Juli (1957) y Ayaviri (1958) — desprendidas de la diócesis de Puno_-, y Sicuani (1959), desprendida de la arquidiócesis del Cusco. La prelatura de Ayaviri - conformada por las provincias de Melgar, Carabaya y Sandia- fue encargada a la congregación de los Sagrados Corazones, y su primer prelado fue monseñor Luciano Metzinger Greff SS. CC.

Este texto presenta una periodificación temporal de cuatro etapas en el trabajo pastoral de la prelatura, desde su creación en 1959 hasta el año 2005, incluyendo un análisis categorial de las fuentes documentales primarias revisadas, además de una breve contextualización política, social y eclesial de influencia directa en su actuación. ${ }^{1}$ Cada fase muestra las diversas concepciones

1. Esta investigación trabaja sobre la exigua documentación de tipo circunstancial o narrativo del archivo pastoral de la prelatura de Ayaviri siguiendo la metodología lógica de Lozano y Mitre (1987), que reagrupa el contenido de los textos en categorías o centros temáticos comunes. Esta opción metodológica está justificada por la diversidad de textos estudiados —anales, decretos, actas, informes - la relativa extensión del período de análisis, y la variedad de categorías que en ellos se utilizan. Así, los textos han sido tratados siguiendo dos criterios: uno, respetando la secuencia cronológica de su 
pastorales subyacentes a lo largo de casi 50 años, así como las correspondientes decisiones y acciones tomadas en asambleas eclesiásticas en torno a diversos problemas sociopolíticos y cuestiones religiosas como el culto popular, los sacramentos, el catecismo y la liturgia.

Se espera, así, que este estudio contribuya a comprender mejor, situándola en un amplio espectro, la actuación de la Iglesia católica en el contexto de los graves problemas políticos, económicos y sociales que aquejaron a la región surandina peruana durante los últimos 50 años.

\section{Tradicional-Conservadora (1959-1969)}

Un punto de partida imprescindible para comprender los esfuerzos y tensiones sociales por los que atravesó el sur andino peruano durante el siglo xx es el llamado «problema de la tierra», el cual ha sido interpretado por la Comisión de la Verdad y la Reconciliación (CVR) como «una gran contradicción que opone el latifundio a las comunidades campesinas» (CVR 2003, tomo IV: 250).

redacción; y el otro, identificándolos y agrupándolos en ejes temáticos que aparecen recurrentemente en la mayoría de los trabajos revisados — aspectos sacramentales, litúrgicos, catequéticos, sociopolíticos e ideológicos-. Es importante precisar que, a diferencia de las otras etapas, la fase políticodemocratizadora (1993-2005) presenta escasísima información primaria, por lo que fue necesario apoyarse en fuentes secundarias confiables. 
Un estudio de Cynthia McClintock (1998: 168) señala que, en el año 1960, la relación entre hombre y tierra era de 21 hectáreas de tierra o pastizales por campesino. Esto correspondía a la mitad de la misma relación en países como Chile, Bolivia y Ecuador, y era una de las proporciones más bajas del mundo. Este panorama socialmente complicado dio lugar al surgimiento de movilizaciones campesinas que se opusieron al crecimiento de las haciendas, al poder terrateniente y al maltrato laboral. En los treinta primeros años del siglo xx, se registraron por lo menos 13 revueltas en poblados como Anta, Azángaro, Canas, Ccapna, Espinar y Lauramarca (CVR 2003, tomo IV: 251).

Otro aspecto que nos puede ayudar a comprender esta problemática es la forma de la estructura social agrícola en el sur andino antes de la reforma agraria de 1969. El informe de la CVR explica que «estuvo basada en una compleja combinación de sistemas y relaciones de trabajo, de tipo asalariado, servil, parcelario, además de múltiples formas mixtas». Por ejemplo, en 1961, de todos los trabajadores del campo, el 60\% de ellos eran parcelarios; el 15\%, arrendatarios; y el 25\%, asalariados permanentes.

Entre 1921 y 1967, esta situación se convirtió en caldo de cultivo para el desarrollo de «proyectos guerrilleros que buscaban dar continuidad al movimiento campesino» (CVR 2003, tomo IV: 253). Sin embargo, estas guerrillas de los años sesenta «no lograron convertirse en el brazo armado del movimiento campesino pues políticamente, eran bastante débiles, ni habían logrado comprender la complejidad de las áreas rurales y urbanas, ni contaban con un modelo de gobierno viable. En el plano militar, no pudieron enfrentar con éxito la ofensiva policial y de 
las fuerzas armadas y demostraron escasa capacidad de influencia en las poblaciones locales» (CVR 2003, tomo IV: 254).

A pesar de ello, se puede mencionar la acción guerrillera del Frente de Izquierda Revolucionaria (FIR) y del Ejército de Liberación Nacional (ELN), que apoyaron una rebelión campesina en Chaupimayo, en los valles de La Convención y Lares de Cusco, liderada por el dirigente campesino Hugo Blanco Galdos. Otro movimiento guerrillero fue el Movimiento de Izquierda Revolucionaria (MIR), que realizó una emboscada contra un destacamento policial en la quebrada de Yahuarina, en 1965.

Durante este periodo, el gobierno de Fernando Belaunde (1963-1968) intentó implementar una reforma agraria, pero que fue lenta e infructuosa, ya que al final del mandato «apenas 214,286.45 has. lograron trámites de expropiación terminados, pero sin financiamiento para terminar el proceso. En total, se beneficiaron 11,760 familias» (CVR 2003, tomo IV: 254).

Considerando estos elementos, la vida en el campo ya era muy difícil, pero en Puno se vio particularmente agravada por períodos de fuertes sequías (años 1955-1956, 1957 y 1964) y de inundaciones por lluvias torrenciales (años 1960, 1962 y 1963). Estos fenómenos acentuaron el proceso de desprestigio de la vida en el campo y beneficiaron el desarrollo de las ciudades. En 1961, se creó un organismo dedicado a organizar y planificar las inversiones de fomento en todo este departamento, que se llamó Corporación de Fomento y Promoción Social y Económica de Puno (Corpuno). 
Ese mismo año se creó la Universidad Técnica del Altiplano. Otro aspecto de importancia cultural para el sur andino, que se produjo en este período, es que la Universidad Nacional San Antonio Abad del Cusco (UNSAAC) comenzó a convertirse en un importante centro de educación superior. De contar con únicamente 5 facultades, entre 1950 y 1977 creció hasta tener 22 programas académicos. Y el número de estudiantes, que en 1950 era 988, se incrementó a 5097 en 1970 y a 14000 en 1980.

\section{Hacia la ortodoxia doctrinal y pastoral}

Los archivos de la prelatura de Ayaviri evidencian claramente la ortodoxia doctrinal y pastoral en este período fundacional, sobre todo en lo referido a la celebración de misas, al comportamiento de los sacerdotes, y a la catequesis y los catequistas. Sin duda, hubo una gran preocupación por implementar las reformas conciliares sobre la liturgia; por ello, se previó una «reforma progresiva, al criterio de cada párroco y según las normas adoptadas durante las jornadas». ${ }^{2}$ También se ordenó que no se realizara ningún cambio en el presbiterio o el altar sin la autorización previa de la Comisión de Liturgia y del prelado. Además, se pidió educar al pueblo sobre la nueva liturgia comenzando por los niños en las escuelas. Y se dispuso la presencia del Santísimo Sacramento en cada iglesia donde hubiera un párroco residencial.

2. Conclusiones de las jornadas pastorales de mayo de 1965 , folio 75 . 
En el año 1965, en la catedral de Ayaviri se celebró la misa del Domingo de Pasión siguiendo las normas litúrgicas establecidas por la «constitución sobre la liturgia» del motu proprio de Pablo VI. ${ }^{3}$ En cuanto al comportamiento de los sacerdotes, se ordenó el uso obligatorio del alzacuello, así como de la sotana en las celebraciones eucarísticas. ${ }^{4}$

Otra gran preocupación estuvo referida a la catequesis y el bautismo de las poblaciones nativas. Por ello, el clero de la prelatura se preguntó si debería rehusarse a bautizar en el caso de que se comprobase que los padres del niño no tenían la fe católica, o si podían exigir a los padres convivientes que, cuando presentaran a sus hijos al bautismo, firmaran una promesa de ponerse en regla con las leyes de la Iglesia. ${ }^{5}$ Concluyeron que sí podían y debían insistir a los padres que regularicen su situación, pero no se podía exigir esto como condición del bautismo de sus hijos. En vez de ello, asumieron el compromiso de dedicarse a la formación de los padres mediante la continua predicación de los días domingo, y una enseñanza antes y después de la ceremonia del bautismo; asimismo, consideraron difundir por la radio charlas en castellano y quechua.

La reflexión en torno a estas preguntas los llevó a la conclusión de que su proceder no podía ser destructivo, pero también que, «considerando la vida de los feligreses», no debían consagrar

3. Decreto de la prelatura de Ayaviri del 4 de abril de 1965, folio 40.

4. Decreto de la prelatura de Ayaviri del 2 de mayo de 1965, folio 1 .

5. Conclusiones de las jornadas espirituales del 1 de agosto de 1967, folio 207. 
como cristianas prácticas que no lo eran. En resumen, los clérigos no debían «rechazar todo, sino evaluar y salvar todo lo que es bueno y erradicar lo que es malo (la parábola de la semilla)». ${ }^{6}$

En esta misma línea de reflexión, tomaron conciencia de la posibilidad de que ellos mismos podían presentar prejuicios y no conocer suficientemente el ambiente. De esta manera, se comprometieron a «tratar de comprender mejor la mentalidad de nuestra gente». ${ }^{7}$ Frente a estas inquietudes, tomaron una serie de medidas prácticas como postergar el bautismo de niños menores de 5 años de edad, pero no generalizar esa regla para todos, aunque el párroco sí podía ser más exigente en caso de que los padres fueran anticristianos. Otras normas eclesiásticas fueron exigirles a los padres de familia una adecuada preparación sacramental (matrimonio-bautismo), evitar anotar como tales en los registros a los hijos naturales y dejar claro que no existe ninguna condición especial para ser admitidos en el bautismo.

De la misma manera, exigieron a los laicos que colaboraban con el trabajo pastoral — fueran catequistas, maestros o alferadosque llevaran una vida cristiana coherente. Para este efecto, solicitaron una «atenta selección de catequistas», ${ }^{8}$ que no fueran menores de 21 años, que tuvieran tercer año de primaria y, de preferencia, que fueran casados; y a los convivientes, se les dio un plazo de tres meses para regularizar su situación.

6. Conclusiones de las jornadas espirituales del 1 de agosto de 1967, folio 207.

7. Conclusiones de las jornadas espirituales del 1 de agosto de 1967, folio 207.

8. Conclusiones de las jornadas pastorales de mayo de 1965, folio 75 . 
En el marco de esta misma preocupación, se estipuló que se formara una escuela de catequesis que estuviera a cargo del párroco «por medio de la prédica y/o enseñanza de religión o al menos control de la misma en escuelas». ${ }^{9}$ Sobre los problemas de la catequesis de la prelatura, se recomendó más contacto con los profesores e incluso se preguntaron por la conveniencia de editar un «libro de los maestros» en el que se dieran explicaciones sumillas de los puntos esenciales de la doctrina. ${ }^{10} \mathrm{Y}$ en el caso de los alferados, ${ }^{11}$ se tomó la decisión de excluir a aquellos que fueran convivientes o anticristianos, como los que se rehusaban a que sus hijos recibieran educación cristiana. También se pidió amenazar con suprimir las fiestas si los alferados «son borrachos», así como aconsejarles recurrir a los sacramentos de comunión y confesión.

En este mismo período fue muy elocuente, respecto del celo evangélico, la decisión de clausurar la capilla de Tahuma, pues «se habrían ejecutado actos de profanación y hechicería en la sacristía». Se justificó esta medida al considerar que «uno de los primeros deberes es vigilar la ortodoxia de la fe y procurar conservar la pureza de la fe». ${ }^{12}$ En el caso de la administración del sacramento de la confirmación por parte de monseñor Metzinger, se observa un fuerte impulso inicial, pero que decayó considerablemente en los años sucesivos. En 1959, se

9. Conclusiones de las jornadas pastorales de mayo de 1965, folio 75 .

10. Conclusiones de las jornadas espirituales del 1 de agosto de 1967, folio 207.

11. Conclusiones de las jornadas espirituales del 1 de agosto de 1967, folio 207.

12. Decreto de la Prelatura de Ayaviri del 21 de marzo de 1966, folio 4. 
registraron 5898 confirmaciones $;^{13}$ en 1961, se alcanzó una cifra similar con 5698 confirmaciones; ${ }^{14}$ pero tres años después (1964), la cifra cae a menos de la mitad: 2376 confirmaciones. ${ }^{15}$ $\mathrm{Y}$ en los años sucesivos, los anales ya casi no registraron las confirmaciones. ${ }^{16}$ Suponemos que, paulatinamente, pierde intensidad este esfuerzo sacramental, y que una de las causas principales podría haber sido la influencia creciente del pensamiento progresista, como veremos más adelante.

\section{La cuestión político-social}

En los años 1965 y 1966, la prelatura se convirtió en objeto de frecuentes visitas de diversos personajes ligados a asociaciones e instituciones «progresistas» del ámbito eclesial europeo. Pero antes de comenzar a mencionarlos, se debe aclarar que durante la mayor parte de este período, monseñor Metzinger no estuvo presente en la prelatura, ya que había viajado a participar en la

13. Registro compuesto de la siguiente manera: 11-04 Sandia 586; 15-04 Corocuyo 298; 17-04 Ananea 61; 19-04 Putambuco 385; 21-05 Macari 558; 17-06 Crucero 229; 18-06 Limbani 262; 20-06 Phara 115; 21-06 Usicuyos 383; 23-06 Ajoyani 126; 25-06 Coasa 303; 11-07 Orurillo 81; 18, 20-07 Macusani 939; 11-10 aillus y ciudad de Ayaviri 127; Antauta 145; 19-10 Olaechea 300; 27-10 Ituarte 42; 3, 5-11 Ayapata 556; 15-10 333; 16-10 Llali 169. Esta información está registrada en el folio 15-19 de los anales de la prelatura de Ayaviri (1959-1974).

14. Anales de la prelatura de Ayaviri (1959-1974), folio 21 (1961).

15. Anales de la prelatura de Ayaviri (1959-1974), folio 37 (1964).

16. Por ejemplo, en los anales de la prelatura de Ayaviri (1959-1974), folio 157 (1966), se registran apenas 261 confirmaciones (21-10 San Juan del Oro 146; 22-10 Yanahuya 36; 23-10 Belén 5; 30-10 Sandia 37; 6-11 Ayaviri 37), folio 159 . 
sesión del Concilio Ecuménico Vaticano II. ${ }^{17}$ Partió de Ayaviri el 2 de setiembre de 1965 y regresó el 24 de diciembre de 1966; ${ }^{18}$ su ausencia de la prelatura fue frecuente por períodos relativamente extensos, no solo por su participación en el Concilio sino también en la asamblea de Medellín y en diversas reuniones celebradas por la Comisión Pontificia de Medios de Comunicación Social. ${ }^{19}$

Durante esos meses de ausencia del prelado, se quedaron en Ayaviri como párroco el padre Nicolás Castell, y como vicario cooperador, el padre Juan María Olivier. ${ }^{20}$ Las instituciones progresistas comenzaron a hacerse presentes en la prelatura a partir del año 1965, cuando llegó Francois Diasson, ${ }^{21}$ «un bretón de pura cepa» enviado por la Compañía Internacional de Desarrollo Rural (CIDR) para efectuar estudios de la realidad campesina de la zona. Dos meses después, comenzó sus actividades la Juventud Agraria y Rural Católica (JARC) a través de Michel Bottler, ${ }^{22}$ quien llegó recomendado por el Movimiento Internacional de la Juventud Agraria y Rural Católica (MIJARC) ${ }^{23}$ con la misión

17. Anales de la prelatura de Ayaviri (1959-1974), folio 93 (1965).

18. Monseñor previamente había ordenado en Roma a Gastón Garatea como sacerdote SS. CC., el día 17 de diciembre de 1966.

19. Cf. anales de la Prelatura de Ayaviri (1959-1974), folio 149 (1965).

20. Anales de la prelatura de Ayaviri (1959-1974), folio 125.

21. Anales de la prelatura de Ayaviri (1959-1974), folio 93 (11 de setiembre de 1965).

22. Anales de la prelatura de Ayaviri (1959-1974), folio 105 (18 de noviembre de 1965).

23. El MIJARC fue fundado en 1954 en Bélgica, con el fin de elevar el nivel de vida de los jóvenes rurales del mundo entero. Es el único movimiento internacional de jóvenes rurales que trabaja a nivel internacional y que agru- 
de comenzar a organizar la JARC peruana. ${ }^{24}$ Posteriormente (1966), se recibió la visita del padre Paúl Dugas, quien se estaba ocupando en Uruguay del apostolado rural. A partir de 1966, se organizaron reuniones y cursos sobre sindicalismo, ${ }^{25}$ como el que se efectuó en el Instituto de Educación Rural (IER) sobre sindicalismo y JARC. ${ }^{26}$ El Movimiento Sindical Cristiano (Moscip) organizó una jornada de estudios en la que participaron dirigentes de 14 haciendas. $^{27}$

Sin embargo, a pesar de esta primera avanzada progresista, no se puede hablar aún de una clara opción política en la prelatura de Ayaviri. Si bien existía una preocupación por la problemática social en ese entonces, los sacerdotes y misioneros trataron de mantener distancia de los movimientos sociales. Eso parece claro al comprobar la posición neutral que manifestó Ayavirii ${ }^{28}$

paba a alrededor de 2 millones de jóvenes de Latinoamérica, Asia, África y Europa. En la década de 1960, el MIJARC adquirió el estatus de consultor de la Organización de las Naciones Unidas para la Educación, la Ciencia y la Cultura (UNESCO) y observador especial en la Organización de las Naciones Unidas para la Alimentación y la Agricultura (FAO). Presentaba una clara opción por los pobres, la justicia social y la redistribución de la riqueza, para lo cual consideraba clave la formación política y participativa de los jóvenes.

24. La Juventud Agraria y Rural Católica del Perú (JARC) es una asociación laica al servicio de la juventud rural del país, creada para dedicarse a la formación y capacitación de jóvenes líderes rurales (varones y mujeres) desde una visión cristiana. Por eso está reconocida por la Conferencia Episcopal Peruana como movimiento que realiza una labor pastoral rural.

25. Anales de la prelatura de Ayaviri (1959-1974), folio 115 (1966).

26. Anales de la prelatura de Ayaviri (1959-1974), folio 123 (28 de enero de 1966).

27. Anales de la prelatura de Ayaviri (1959-1974), folio 147 (4 de julio de 1966).

28. Anales de la prelatura de Ayaviri (1959-1974), folio 103 (1965). 
frente a los actos de violencia ocurridos en noviembre de 1965 en Juliaca. El 15 de noviembre de ese año, en el teatro Municipal de Ayaviri se realizó un cabildo abierto en el que se abordó el tema de los luctuosos sucesos de Juliaca y la rivalidad que la enfrentaba con Puno: «Ayaviri ratifica su posición de neutralidad, limitándose a: a. Mandar un comunicado telefónico a Lima en contra de la ley de amnistía propuesta en el congreso para las personas implicadas en los sucesos (en primer lugar el alcalde de Juliaca). b. A declarar a los hermanos Cáceres personas no gratas en el departamento». ${ }^{29}$

En esta etapa, la población en su conjunto mostró gran respeto por las autoridades eclesiásticas, y la relación entre ellas también era bastante satisfactoria. ${ }^{30}$ La prelatura recibió a importantes autoridades religiosas, familias aristócratas y autoridades políticas. Por otro lado, en esta etapa, el clero en su conjunto no parece adoptar una postura clasista en sus relaciones institucionales, pues incentiva buenas relaciones tanto con los sectores pudientes como con el campesinado, sin mayor problematización

29. Estos hechos, que sucedieron en el marco del conflicto por la tierra, se encuentran desarrollados en Apaza Quispe (2001: 184).

30. El cardenal y primado del Perú Juan Landázuri Ricketts llegó el 8 de mayo de 1964. A él y a su comitiva se les dio una «recepción triunfal en la estación de Ferrocarril Central». Lo acompañaron en esa oportunidad monseñor Edward Fedders, prelado de Juli, y Julio González Ruiz, obispo de Puno. Dos años después (1966), fue el nuncio apostólico monseñor Rómulo Carboni quien visitó la prelatura del 13 al 19 de octubre. Esta visita fue considerada todo un acontecimiento que involucró a las autoridades políticas y militares, así como a toda la población, quienes le dieron una cálida recepción con cantos, bailes, comidas, etcétera. El nuncio visitó además Orurillo y Macarí. 
moral. Por ejemplo, en 1965, representantes de la prelatura sostuvieron reuniones con hacendados sobre la creación del acervo parroquial diocesano. ${ }^{31}$ En ese mismo año, el vicecónsul de Estados Unidos en Arequipa se hospedó en la prelatura cuando pasó por Ayaviri en tránsito hacia el Cusco. ${ }^{32}$ Y también en 1965, antes de partir a las sesiones conciliares, monseñor Metzinger ofreció en la Ciudad de los Jóvenes un cóctel de despedida a las autoridades y a un grupo de hacendados. ${ }^{33}$ Se acogió a la familia Ferreyros (1966), ${ }^{34}$ y se ofreció en la prelatura un almuerzo para ellos y la familia Rey. Hubo participación eclesiástica en ceremonias políticas como la juramentación del nuevo alcalde, en 1967, a la que asistieron el obispo prelado y el párroco padre Rica. ${ }^{35}$ Ese mismo año, todos los religiosos de Ayaviri fueron de paseo a la hacienda San Juan. ${ }^{36}$ En 1965, monseñor Metzinger bendijo el club de la Ciudad de los Jóvenes, ${ }^{37}$ que desde su fundación, en 1961, aportó colaboradores para la catequesis, profesores del IER $^{38}$ y militantes sindicales. El obispo también dirigió un discurso en contra de las acusaciones de Luis Valencia Pacheco,

31. Anales de la prelatura de Ayaviri (1959-1974), folio 89 (14 de agosto de 1965).

32. Cf. anales de la prelatura de Ayaviri (1959-1974), folio 93 de 1965. El alcalde del pueblo había solicitado que se hospedara el funcionario estadounidense en la prelatura, pues esta «ofrece el más decente alojamiento en Ayaviri».

33. Anales de la prelatura de Ayaviri (1959-1974), folio 93 (28 de agosto de 1965).

34. Anales de la prelatura de Ayaviri (1959-1974), folio 143 (28 de julio de 1966).

35. Anales de la prelatura de Ayaviri (1959-1974), folio 167 (9 de abril de 1967).

36. Anales de la prelatura de Ayaviri (1959-1974), folio 193 (7 de mayo de 1967).

37. Anales de la prelatura de Ayaviri (1959-1974), folio 78 (15 de agosto de 1965).

38. El 15 de junio de 1964 se funda el IER, que en sus inicios no tenía una orientación ideológica sino pastoral y de promoción de artesanos. De 1971 en adelante, su función se centrará sobre todo en la formación de promotores 
secretario del comité departamental aprista de Puno, quien declaró que los comunistas se habían infiltrado eficazmente en las instituciones religiosas sociales de la Iglesia en el departamento de Puno.

Este fue el tenor de la actividad pastoral de la prelatura hasta aproximadamente el año 1969, en el que se inició un proceso de revisión y reflexión de los métodos pastorales «tradicionales». El nuevo enfoque pretendía la inculturación del Evangelio en las culturas locales. Este proceso estuvo muy influenciado desde sus inicios por visiones ideológicas ligadas al indigenismo y al culturalismo. Paradójicamente, la mirada desde esta perspectiva supuso también incomprensiones contra expresiones culturales muy propias de la religiosidad popular.

\section{INDIGENISTA-CULTURALISTA (1970-1974)}

En el Perú, este período estuvo marcado por un contexto social en el que se aceleraron los procesos de migraciones y urbanización. Este fenómeno afectó también al sur andino. En el caso del departamento de Puno, fueron las ciudades de Puno y Juliaca las que comenzaron a mostrar un mayor desarrollo. Esta última casi triplicó su población en apenas 20 años: pasó de tener 30890 habitantes en 1960 a 87651 en 1981. En esta ciudad comenzó a consolidarse una burguesía comercial que fue

sociales, a la vez que en capacitación y asistencia técnica agropecuaria a los campesinos. Cf. Tovar (ed.) (2006: 408). 
desplazando el poder económico regional de la antigua clase terrateniente. Sin embargo, fue la reforma agraria implementada por el gobierno militar del general Juan Velasco Alvarado en 1969 la medida que más afectó las actividades agrícolas y la vida en el campo. Como lo indican diversos estudios (McClintock 1989, Masterson 1991: 253, Klarén 2004: 421), la mayoría de los campesinos de la sierra sur no se beneficiaron en nada con la reforma agraria del gobierno militar: después de esta, apenas una cuarta parte de la población rural había conseguido acceso a la tierra, lo que significaba que el Perú tenía, junto con la India, «la peor relación hombre-tierra del mundo (apenas 0.18 hectáreas de tierras cultivables por persona)» (Klarén 2004: 422).

En el caso particular de Puno, la reforma agraria creó empresas asociativas y así fusionó las tierras más productivas en una sola administración centralizada. La consecuencia fue que el 80\% de las tierras y pastos naturales quedaron en manos de estas asociaciones, mientras que las comunidades campesinas únicamente recibieron el 2,5\% de las tierras. Todo esto generó un malestar permanente que se volcó en protestas campesinas recurrentes contra las empresas asociativas, sobre todo durante la década de 1980.

También hay que reconocer que después del golpe militar de 1968, poco a poco un sector de la Iglesia fue optando por las reformas sociales realizadas por el gobierno militar. Un claro ejemplo es el comunicado de respaldo a la Ley de Reforma Agraria. Este período de la historia de la Iglesia en el Perú, que se extiende de 1968 a 1975, es llamado por Jeffrey Klaiber (1988: 335) la Iglesia social-política; fue una etapa muy influenciada por «las doctrinas desarrollistas en boga» y se caracterizó por 
un afán de expansión exterior y por el fomento de proyectos de desarrollo, como las cooperativas del padre MacLellan en Puno.

Klaiber advierte que en este proceso de modernización y de impacto del Concilio Vaticano II, la Iglesia pasó a ocupar un papel protagónico durante el régimen del dictador Velasco, pues intervino directamente en muchas de las reformas que afectaron al país entero y actuó como legitimadora de los cambios sociales. En esta época surgió la corriente vinculada a la Teología de la Liberación, cuyo hito inicial fue la primera exposición que realizó sobre esta el sacerdote peruano Gustavo Gutiérrez, en julio de 1968. Hay que aclarar que, como señala Luis Pásara (1986: 56), la Teología de la Liberación no solo encontró «coincidencias» con el marxismo sino que «un cierto número de conceptos centrales» de esta teología «tendrían que ser descritos como "préstamos" del pensamiento marxista»; y como ejemplos para sostener esta afirmación considera «la aceptación del condicionamiento económico e ideológico sobre los valores culturales, la teoría de la alienación del trabajo — tomada del joven Marx-, la noción de praxis, la necesidad del conflicto social para promover cambios y la imposibilidad de la neutralidad política en la lucha de clases originada en la propiedad privada de los medios de producción, así como la inevitabilidad del socialismo, entendido como la construcción de una sociedad sin clases (Smith 1982: 230; Robb 1978: 312-316)».

\section{La inculturación del Evangelio en la Iglesia andina}

En este contexto, y en consonancia con algunas interpretaciones ideológicas hechas sobre la Asamblea Episcopal de Medellín 
(1968) —además de otros sucesos sociopolíticos que conmocionaron al mundo ${ }^{39}$ - , se impulsó el proceso de inculturación del Evangelio en la Iglesia andina.

Como parte de este proceso, monseñor Ricardo Durand, obispo del Cusco, fundó en 1969 el Instituto de Pastoral Andina (IPA), cuyo primer director fue el padre Luis Dalle. ${ }^{40} \mathrm{Al}$ poco tiempo, se publicó el primer número de la revista Allpanchis Phuturinqa. A partir de una lectura «culturalista» de Medellín,

[...] el IPA y la revista Allpanchis se convirtieron en los grandes impulsores tanto de una investigación seria de las culturas Quechuas y Aymaras, como de la oferta de una formación adecuada para los agentes pastorales de la zona dentro de las categorías culturales propias [de tal manera que] la cultura y, de modo especial, las creencias religiosas acapararon la atención del momento. Predominó el enfoque culturalista en la forma de enfrentar los problemas. La

39. Tal como el mayo francés de 1968, una ola de protestas estudiantiles y obreras que conmovió al mundo entero. Este movimiento cuestionaba radicalmente el statu quo imperante y originó la adhesión de muchas personas a causas de izquierdas como el comunismo, el rechazo a la guerra de Vietnam, el anarquismo o el situacionismo. Otros vieron los hechos como una oportunidad para cambiar a la «vieja sociedad» en muchos aspectos sociales como los métodos educativos y la libertad sexual. Una minoría de manifestantes, como el grupo Occident, apoyaba causas de extrema derecha.

40. En esa época, el padre Dalle —entonces sacerdote y luego obispo— visitaba frecuentemente la prelatura de Ayaviri. Según los anales de la prelatura de Ayaviri (1959-1974), su primera llegada se registra el 5 de mayo de 1964 (folio 35); otras visitas se registran el 24 de diciembre de 1964 (folio 50), el 10 de marzo de 1966 (folio 125), el 27 de julio de 1967 (folio 195), entre otras. 
iglesia se fue esbozando un perfil político como defensora de las culturas marginales (González 1982: 19-20).

Por su parte, el por entonces padre Dalle — quien, posteriormente, sería nombrado obispo- escribió: «A los misioneros del Ande, el Concilio y el mundo indígena lanzan el mismo reto: ¿tendremos la verdadera caridad, la imaginación, el espíritu de creatividad necesarios para volver a escribir nuestros catecismos, nuestros sermonarios, nuestra espiritualidad, nuestra teología, en el contexto de la Pachamama, de los Apus, de las estrellas?» (Dalle 1969: 154).

En los años que siguieron, este discurso se radicalizó aún más, como se puede apreciar en un artículo escrito por el padre Jaime Regan S. J. sobre los ritos indígenas:

En vez de hacer una catequesis aislada de la experiencia religiosa del campesino, sería mucho de provecho hacer algo semejante a lo que hicieron los judíos. Durante el rito indígena podríamos usar las acciones y las cosas que ellos entienden bien, como la base de una catequesis sobre los ritos cristianos (Regan 1971: 206).

Este proceso culturalista adquirió un carácter «científico» con estudios etnográficos como los realizados en 1973 por Manuel Marzal, quien, según José Luis González:

[...] hacía un buen análisis del problema y, constatando que la construcción de una Iglesia realmente autóctona estaba por iniciarse, señalaba pistas para una encarnación 
doctrinal, ritual, ética, organizativa. Eran perspectivas audaces que, conservando la libertad crítica, abrían el camino para una pastoral que incorporase aspectos tan importantes como la mitología andina, las creencias en torno a la muerte, la legitimidad del Servinacuy, los ritos agropecuarios y un sacerdocio casado acorde con los patrones culturales andinos. Ciertamente, quedaban todavía otros aspectos más profundos como la reformulación de los rituales oficiales (misas y sacramentos) desde los códigos simbólicos indígenas, la reorganización del año litúrgico en relación con el ciclo agrario, la reelaboración del cuerpo doctrinal cristiano desde el pensamiento (ethos, cosmovisión, filosofía, historia, etc.) andino (González 1982: 21).

La clara intención de inculturación debía, contradictoriamente, suprimir costumbres seculares que se habían asentado durante siglos en las comunidades andinas. Con una visión apriorística y acultural de la realidad, se dictaminó la supresión del cargo de mayordomo en un pueblo tan profundamente religioso como Ayaviri, el 99\% de cuya población, entre los años 1970 y 1973, profesaba la religión católica. Invocando una legítima preocupación por la persona del mayordomo, la norma eclesiástica acabó imponiéndose a la inveterada organización comunal para el culto:

Considerando que existe todavía en muchas parroquias de esta prelatura, la costumbre inmemorial de nombrar feligreses de esta parroquia para que, con el nombre de mayordomo, cuiden el templo y realicen otros trabajos en la parroquia, sin percibir sueldo o remuneración por estos 
servicios y labores. Considerando que esta costumbre es lesiva a la dignidad de la persona y de sus derechos reconocidos por la ley natural y positiva. Oído el consejo pastoral, del consejo presbiteral y de los consultores diocesanos en sus respectivas sesiones del 6 y 7 del presente mes. Decretamos: 1. suprimir la antigua costumbre del mayordomo en todas las parroquias de la prelatura a partir de la fecha. 2. Los señores párrocos, con los señores ecónomos, las autoridades locales y todo el pueblo, acordarán en cada parroquia las disposiciones convenientes para que el templo sea cuidado en forma debida. ${ }^{41}$

Con una lógica acultural similar, en mayo de 1973, monseñor Luis Dalle, a través de un decreto eclesiástico, suprimió la celebración de las misas en los planteles educativos, costumbre muy tradicional en la educación local. ${ }^{42} \mathrm{El}$ decreto ordenó la supresión de las misas en los diferentes planteles de educación, principalmente en «los programas de inauguración del año escolar, de clausuras, de aniversarios, del día del colegio»». ${ }^{43}$ Esta norma también retiró la primera comunión del ámbito escolar y dispuso que esta «se realizara fuera del ambiente escolar y bajo la plena responsabilidad de los padres de familia y del párroco». ${ }^{44}$ Estas medidas se justificaron en el marco de la idea de «una sociedad pluralista» ${ }^{45}$ en la que $\langle$ resulta injusto imponer deter-

41. Decreto de la prelatura de Ayaviri del 8 de enero de 1970, folio 7.

42. Decreto de la prelatura de Ayaviri del 21 de mayo de 1973.

43. Decreto de la prelatura de Ayaviri del 21 de mayo de 1973.

44. Decreto de la prelatura de Ayaviri del 21 de mayo de 1973.

45. Decreto de la prelatura de Ayaviri del 21 de mayo de 1973. 
minados actos de culto que no sean aceptables no significativos, para todos los sectores de la comunidad». ${ }^{46}$

Sin embargo, el discurso culturalista para la inculturación en la Iglesia andina perdió fuerza y trascendencia debido a la irrupción de la Teología de la Liberación, cuyo análisis marxista de la realidad reclamaba urgentemente el cambio de las estructuras sociales. Es necesario precisar que, en la siguiente etapa, no desaparece del todo la temática cultural; sin embargo, se reduce significativamente la atención teórica y práctica que se había logrado durante este período. En el discurso liberacionista, se observa que pierde densidad la idealización y romantización de las culturas andinas.

\section{Político-liberacionista (1975-1992)}

A nivel nacional, esta etapa estuvo marcada por la vorágine de violencia desencadenada por la banda terrorista Sendero Luminoso, que representó la más grande amenaza a la paz y la democracia, llegando a ejercer un control virtual sobre el $40 \%$ del territorio nacional.

¿Qué significó para el sur andino y para la Iglesia de la región este período de aguda violencia? La CVR considera que el terrorismo en el norte de Puno «está vinculado a la crisis del sistema asociativo creado por la reforma agraria y a la lucha por

46. Decreto de la prelatura de Ayaviri del 21 de mayo de 1973. 
la reestructuración democrática de la propiedad de la tierra, en cuyo conflicto se vieron involucrados diversos actores políticos y sociales (PCP-PCP-SL, las Fuerzas Armadas y Policiales, la Iglesia Sur Andina, las organizaciones campesinas, el gobierno, las empresas asociativas y los partidos políticos)» (CVR 2003, tomo IV: 258). En el caso del sur andino, la Iglesia, desde mediados del siglo pasado «dio alta prioridad a la promoción del campesinado y la defensa de sus derechos» (Klaiber 1997: 263). Fue por eso que, en 1983, el presidente Belaunde Terry acusó a las ONG y a la Iglesia de estar al servicio de la subversión. Y en 1987, el alcalde de Puno acusó a la Iglesia puneña de «proteger y encubrir» a Sendero Luminoso, señalando directamente a las religiosas y los sacerdotes extranjeros, a quienes acusó de ser simpatizantes de la subversión.

Para muchos, era claro el acento de izquierda política que la Teología de la Liberación le había impreso al trabajo pastoral del sur andino. Tanto así que la Iglesia en esta región era considerada proizquierdista marxista y procomunera. Así lo explica la revista Caretas (1986): «La Iglesia Sur Andina no oculta su simpatía hacia la izquierda marxista local, cuenta con una de las emisoras de radio más potentes de la zona, Onda Azul y ha argumentado a favor de la reestructuración de tierras en castellano, quechua y aymara. También tienen por cierto, programas educativos» (citado en CVR 2003, tomo IV: 278). A partir de 1986, la Iglesia en Puno, Ayaviri y Juli fue muy activa en la organización de marchas y eventos por la paz a los que convocaba a organizaciones populares, a la Policía y a los militares; asimismo, se pronunció en contra de la violencia, llegando incluso a condenar con nombre propio a Sendero Luminoso. 
Además, se comenzaron a organizar las vicarías de la solidaridad en Puno (1986), Ayaviri (1986) y Juli (1988).

La CVR (2003, tomo III 385-390) señala que la Iglesia católica fue hostigada y atacada por Sendero Luminoso mediante pedidos de cupos, vigilancia y seguimiento a sus miembros, ataques verbales o escritos en volantes y pintas, limitación de las actividades eclesiales e intentos de infiltración en estas, amenazas de muerte, atentados contra obras de la Iglesia, y asesinatos de sacerdotes, religiosos y laicos.

Y enumera los siguientes como los principales hechos de violencia contra la Iglesia en el sur andino: en julio de 1984, se produce un intento de asesinato del padre Francisco Gmür, párroco de Putina. En mayo de 1985, el templo de Azángaro sufre un atentado. En agosto de 1986, desconocidos vuelan la antena de radio Onda Azul en Puno; ese mismo mes, colocan una carga explosiva en el Departamento de Solidaridad en Ayaviri. En octubre de 1986, hubo un atentado terrorista en el local parroquial de Asillo (Azángaro). En mayo de 1989, Sendero destruye totalmente el local del IER de Waqrani (Ayaviri). En ese mismo mes, amenaza a monseñor Francisco d'Alteroche. El 24 de junio de 1990, Sendero asesina al catequista campesino Florentino Soncco, en el distrito de San Antón (Azángaro). En febrero de 1991, el local de Cáritas en Azángaro es atacado con explosivos.

El número de muertos y desaparecidos reportados a la CVR en Puno fue de 441 víctimas entre los años 1980 y 2000. Para tener puntos de comparación, referiremos que durante el mis- 
mo período el terrorismo en el Cusco se cobró 134 víctimas; y en Apurímac, 813 víctimas. El 89,3\% de muertes y desapariciones en Puno (394) ocurrieron apenas en siete años, entre 1986 y 1993. Los peores años fueron 1989 y 1992.

\section{Una nueva lectura religiosa}

En los documentos revisados de la prelatura de Ayaviri correspondientes a este período, se observa la prevalencia del discurso «liberador» de corte marxista, y es claro también que se adoptó la metodología «ver-juzgar-actuar» ${ }^{47}$ como medio privilegiado para aproximarse a la realidad. En consonancia con ello, todas las asambleas, reuniones o consejos registrados en las actas empezaban con un diagnóstico de la realidad nacional y local en tres dimensiones fundamentales: económica, sociopolítica y cultural-religiosa. En todas ellas, se decodificó la realidad en términos sumamente conflictivos. Por ejemplo, en la reunión del Consejo de Presbiterio de 1976 — con la presencia de monseñor Dalle y el padre Gastón Garatea-, se interpretó la relación política en términos de oposición entre pueblo y no pueblo:

Autoridades de gobierno: poseedores del poder económico, comercio. Autoridad vertical dominante, impuesta al pueblo. Grupo cerrado; no escucha; engaña con promesas; mira a Lima. Autoridades de comunidades campesinas: aunque elegidas por la base son dependientes y frustradas ante el gobierno y manipulaciones por las ligas agrarias...

47. Actas de la asamblea de la prelatura de Ayaviri (1986), folio 109. 
¿Quién obedece? Un pueblo que espera la solución de sus problemas acercándose a las autoridades. No es escuchado y difícilmente puede hablar, al servicio de estructuras políticas que lo dominan. Poco sabe de los «porqué». No se arriesga. Suplica. En condiciones de salud, educación, nutrición, vivienda, cada vez más deficientes. Con formas de explotación interna a partir del "padrinazgo», de las diferencias sociales y de la marginación de la mujer. Sin conciencia política. Pero está iniciándose su proceso de cambio histórico. ${ }^{48}$

En cuanto al diagnóstico de los aspectos religiosos, la asamblea señaló que la expresión religiosa de los hombres del campo «refleja su dualidad social: "no-pueblo" (autoridades)-"pueblo" (sectores oprimidos)». ${ }^{49} \mathrm{Y}$ ante esa perspectiva, se evidenció la «urgencia de integrar lo político, social, económico y cultural en el contexto religioso del pueblo». ${ }^{50}$ Esta misma dialéctica conflictual se aplicó a la Iglesia, y en ella se interpretó la existencia de un sector aliado al poder que utilizaba el Evangelio «para defender y justificar la dominación», de otro sector conciliador «orientado hacia cierto desarrollismo, asistencialismo y paternalismo»y, finalmente, de un sector «comprometido con el pueblo», a cuyos integrantes llamaron «profetas defensores de

48. Actas del Consejo de Presbiterio del 30 de noviembre al 3 de diciembre de 1976, folio 75 .

49. Actas del Consejo de Presbiterio del 30 de noviembre al 3 de diciembre de 1976, folio 77 .

50. Actas del Consejo de Presbiterio del 30 de noviembre al 3 de diciembre de 1976, folio 77 . 
los vencidos». ${ }^{51}$ Muy en sintonía con este nuevo enfoque sociologizado, se invitó a desarrollar una teología propia, que ellos valoraron como la más adecuada para la realidad andina:

[...] no podemos seguir fomentando el monopolio de la interpretación de la Biblia por el pueblo. El pueblo ha iniciado su apropiación de la palabra de Dios y va concretizando caminos históricos de salvación $[\ldots]$ hay que buscar una presencia verdaderamente evangélica de la Iglesia en medio de las masas oprimidas y cortar con todo adoctrinamiento de valores morales ajenos al pueblo y poco humanistas. ${ }^{52}$

En esta misma reflexión, se propusieron como ideales por realizar «Partir de la lectura del evangelio, desde los pobres, en nuestra práctica pastoral. Impulsores del cambio social y no manipuladores. Cuestionar nuestra solidaridad con el pueblo, no sólo de corazón y de palabra, sino como expresión de nuestro ser y vivir con el pueblo». ${ }^{53}$ Toda esta nueva, audaz y conflictiva propuesta hermenéutica se vio reflejada en una nueva dinámica pastoral, tal como lo manifiesta el Plan Pastoral de la Prelatura de Ayaviri de 1977. Este plan se elaboró en Chucuito, del 18 al 22 de abril de ese año, con la presencia de monseñor Luis Dalle:

51. Actas del Consejo de Presbiterio del 30 de noviembre al 3 de diciembre de 1976, folio 79.

52. Actas del Consejo de Presbiterio del 30 de noviembre al 3 de diciembre de 1976, folio 79 .

53. Actas del Consejo de Presbiterio del 30 de noviembre al 3 de diciembre de 1976, folio 81. 
[...] actitud fundamental del Agente Pastoral: considerando que no hay cultura superior, es una actitud de ESCUCHA DEL PUEBLO, información, mentalidad, análisis de la situación concreta, conflicto, sincretismo, religioso. Opción fundamental por el pobre. Relectura de la Biblia y la tradición desde el pobre que remueve las perspectivas doctrinales con tal que restituya texto bíblico en su contexto histórico. ${ }^{54}$

Como acciones pastorales, se plantearon una serie de propuestas que, lejos de estar relacionadas con actividades como la catequesis o los tradicionales ritos católicos, se vinculaban más bien con actividades políticas:

Estudiar y hacer conocer los derechos del hombre como persona (derechos del pobre), hacer conocer las leyes, sus alcances, sus límites. Denunciar acciones contra [...] los derechos humanos: atropellos individuales o políticos; reivindicación huaccho ['marginal' en quechua]. [...] denunciar los atropellos relacionados a precios agrícolas que favorecían a los ricos; también las violaciones a la legislación laboral como los despidos intempestivos o la inseguridad laboral [...]; lo mismo en caso de atropellos a la libertad como la supresión de garantías, y la intimidación a los grupos que se formaban o se expresaban [...]; y en el aspecto cultural, aquellas circunstancias de represión cultural, y las estructuras deshumanizantes. ${ }^{55}$

54. Actas del Plan Pastoral de la Prelatura de Ayaviri del 18 al 22 de abril de 1977.

55. Actas del Plan Pastoral de la prelatura de Ayaviri del 18 al 22 de abril de 1977. 
Este intento de redefinición de las estructuras eclesiales también se reprodujo en una nueva conceptualización del servicio ministerial. Esta propuesta se basó en la idea de que «todo servicio que ayuda al hombre a pasar de condiciones menos humanas a condiciones más humanas, puede ser reconocido como ministro». ${ }^{56}$ Según este enfoque, se llegó aun a considerar como «ministros» a los curanderos andinos, a quienes se llamó «promotores de salud». ${ }^{57}$ Estas ideas fueron expuestas en 1979 por el padre Martín Murphy — sacerdote de la congregación Maryknoll que trabajaba en Ayacucho- en una asamblea de la prelatura que contó con la presencia de monseñor Luis Dalle y el padre Gastón Garatea, entonces padre provincial de los Sagrados Corazones. ${ }^{58}$ En esa reunión, se cuestionó el «sacerdocio ministerial uniformizado» y se avaló la tendencia de que los ministerios abarquen una "gran diversificación». ${ }^{59}$

La redefinición del ministerio en el fondo revela una redefinición más profunda: la de la Iglesia. En esta misma reunión, se dividió a la Iglesia en cinco modelos: ${ }^{60}$ Iglesia institución; Iglesia pueblo de Dios; Iglesia sacramento, signo de salvación; Iglesia profé-

56. Actas de la asamblea de la prelatura de Ayaviri del 22 al 27 de abril de 1979, folio 2 .

57. Actas de la asamblea de la prelatura de Ayaviri del 22 al 27 de abril de 1979, folio 2 .

58. Actas de la asamblea de la prelatura de Ayaviri del 22 al 27 de abril de 1979 , folio 2 .

59. Actas de la asamblea de la prelatura de Ayaviri del 22 al 27 de abril de 1979 , folio 2 .

60. Actas de la asamblea de la prelatura de Ayaviri del 22 al 27 de abril de 1979, folio 3 . 
tica; e Iglesia servidora. Los asambleístas criticaron el modelo de Iglesia institución y revaloraron el modelo de Iglesia pueblo de Dios. Según este esquema, el modelo Iglesia institución concebía a la Iglesia como una sociedad perfecta y piramidal, que estaba por encima del mundo —ubicado en la base de la pirámidey se confundía con el reino de Dios. Siguiendo el esquema de la mencionada asamblea, en la Iglesia institución los ministros se percibían esencialmente como una jerarquía por encima del pueblo, actor meramente pasivo y receptor de sus directivas; el servicio religioso que se prestaba estaba dirigido a la conversión del individuo.

En contraposición, y siempre siguiendo el punto de vista de la asamblea, el modelo de Iglesia pueblo de Dios estaba basado en una concepción eclesial intramundana: se veía dentro del mundo, que constituye el reino de Dios. Desde adentro, era signo de salvación. El reino era coextensivo al mundo. Uno pertenecía a la Iglesia como miembro de una comunidad y no de una sociedad. Los miembros de la comunidad eclesial — papa, obispos, sacerdotes, etcétera - cumplían un papel de servicio hacia la comunidad. Se trataba de ayudar al hombre a pasar de condiciones menos humanas a más humanas, para que se acerque de veras a ser imagen de Dios. Se respetaba la conciencia de cada hombre independientemente de que pertenezca o no a la Iglesia. Según este modelo, el pueblo es activo y la jerarquía coordina. Los ministerios se hacen más extraeclesiales. La organización es necesaria, mas no se confunde como institución. La organización vive y crece como un cuerpo; los cambios son posibles, mientras que la institución es fija y estática. 
Con esta propuesta de nueva Iglesia, la misma asamblea recogió la interpretación de que la estructura de la Iglesia peruana era esencialmente criolla y costeña. Las vocaciones salieron de esta reducida capa de la sociedad y no del pueblo nativo mayoritario, porque siempre existió este prejuicio desfavorable para con el mundo indígena. Según esta visión, la Iglesia peruana se identificaba con la clase burguesa, que por ser reducida y minoritaria dio muy pocas vocaciones, y por ello no se logró nunca formar una Iglesia autóctona ni congregaciones autóctonas. ${ }^{61}$

\section{Cáritas, ¿un arma del imperialismo?}

Respecto del debate que se suscitó en 1979 en torno a la entrega de alimentos que Cáritas hacía en favor de muchas familias pobres, conforme a sus presupuestos ideológicos, los responsables de la prelatura decidieron rechazar el abastecimiento proveniente de esta institución de la Iglesia católica, con lo cual dejaron en el desamparo a muchas familias que dependían de estos alimentos para su supervivencia. Se llegó a calificar la entrega de víveres como «una falacia de ayuda», «una caridad con uñas», y propiamente a Cáritas se la llamó «un arma en manos del imperialismo y de las clases dominantes nacionales para acallar la voz del pueblo». ${ }^{62}$

61. Actas de la asamblea de la prelatura de Ayaviri del 22 al 27 de abril de 1979, folio 8 .

62. Actas de la asamblea de la prelatura de Ayaviri del 18-23 de octubre de 1979, folios 18-19. 
El destino de los alimentos de Cáritas se resolvió en una asamblea de la prelatura realizada en octubre de ese año. ${ }^{63} \mathrm{El}$ padre Francisco d'Alteroche abrió el debate y leyó un documento de monseñor Luis Dalle en el que se reconocía que en el pasado estas donaciones fueron necesarias, pero que pensaba que había llegado el momento de «acabar con los víveres de Cáritas». En esa reunión, el agente pastoral Alipio Canales explicó el funcionamiento de la organización nacional-internacional de Cáritas con relación al Estado peruano y la Iglesia, e informó que en ese momento funcionaban en la prelatura de Ayaviri unos 50 proyectos de desarrollo que recibían ayuda en víveres por parte de Cáritas. Para analizar este tema, tomaron la palabra 23 participantes de la asamblea, la gran mayoría de los cuales resaltó el aspecto negativo que tenían estas donaciones sobre el pueblo.

Para justificar esta decisión, la asamblea desarrolló una serie de argumentos de tipo pastoral, sociocultural y sociopolítico. Se expuso que la pastoral con víveres no estaba en la línea de las orientaciones del plan pastoral de la prelatura. También se citó un pasaje del documento de la Conferencia Episcopal de Puebla: «Suprimir las causas y no sólo los efectos de los males, y organizar los auxilios de tal forma que quienes los reciben se vayan liberando progresivamente de la dependencia externa y se vayan bastando por sí mismos», ${ }^{64}$ y con ello aseguraron

63. Actas de la asamblea de la prelatura de Ayaviri del 18-23 de octubre de 1979, folios 18-19.

64.. Documento de Puebla número 1146. 
que «los víveres no lograrán su fin que es animar al pueblo a ser agente de su propia liberación». ${ }^{65}$ Explicaron que los víveres de Cáritas eran un factor de división al interior de las comunidades y entre comunidades, y que destruían expresiones de la organización tradicional de los comuneros, como la faena. Otros argumentaban que esta ayuda caritativa convertía al pueblo en «un pueblo de mendigos» porque retiraba a los padres de familia la responsabilidad que tenían en la educación de sus hijos; y a las autoridades locales, su responsabilidad en el desarrollo de su comunidad.

Un argumento sociopolítico fue considerar a Cáritas como un arma en manos del imperialismo y de las clases dominantes nacionales para acallar la voz del pueblo. Justificaron sus sospechas argumentando que un $80 \%$ de las donaciones provenían del Gobierno norteamericano y que tal ayuda no podía ser «inocente». En ese sentido, también mostraron sospechas de que los víveres contuvieran anticonceptivos.

La votación fue realizada mediante el voto secreto. De los 25 asambleístas con derecho a voto, 22 estuvieron de acuerdo con la propuesta de monseñor Luis Dalle de no aceptar más pedidos de ayuda de víveres provenientes de Cáritas Perú. Se determinó que los bienes que quedaban iban ser repartidos hasta que se agotaran en los proyectos en curso; y a partir de ese momento, se propuso orientar a la población a realizar los trabajos necesarios por su propio esfuerzo.

65. Actas de la asamblea de la prelatura de Ayaviri del 18-23 de octubre de 1979, folios 18-19. 
Durante los siguientes años, se observó el mismo tenor de diagnóstico de la realidad y el planteamiento de las acciones necesarias para enfrentarla. Es posible notar cómo se fue radicalizando la crítica contra la estructura misma de la Iglesia de la que ellos formaban parte. Un ejemplo muy elocuente en este sentido fue el análisis de la realidad eclesial que realizó el padre Garatea en una asamblea, en la que llegó a calificar de «papolatría» la obediencia que los obispos deben al pontífice, y criticó que no se comprendiera que «unos indios puedan hacer teología partiendo de su realidad»:

Los obispos después de 1975 son muy verticales, solo repiten lo que el papa dice, bien orquestados por el Nuncio en una verdadera «papolatría» y cambian el sentido del CeLAM [Consejo Episcopal Latinoamericano] (todo esto a partir de 1972). Con Mons. López Trujillo, que llegará a ser cardenal y presidente de la Conferencia Episcopal Colombiana, organiza e impone una vuelta a la disciplina, pasando por la batalla de 1978-1979. ${ }^{66}$

Con duros calificativos, el padre Garatea cuestionaba, además, la labor pastoral de varias instituciones eclesiales católicas como el Opus Dei, Comunión y Liberación, y Sodalitium Cristianae Vitae, a las que acusaba de buscar «una Iglesia poderosa más que servidora»y de ser «mantenedoras del sistema». ${ }^{67}$ Sus críticas se extendieron también contra monseñor Ricardo Durand Flórez, quien en ese momento era arzobispo del Cusco y representaba

66. Actas de la asamblea de la prelatura de Ayaviri (1986), folios 146-148.

67. Actas de la asamblea de la prelatura de Ayaviri (1986), folio 147. 
una de las voces más críticas respecto de las desviaciones doctrinales de la Teología de la Liberación. Los asambleístas utilizaron argumentos que revelan una concepción de la Iglesia dividida entre la estructura institucional y la comunidad carismática:

[...] los Obispos al separarse del pueblo, más cómodos se sienten y con más poder, agrandando más y más el desnivel entre jerarquía y pueblo. Las monjas siguen comprometidas y los curas, religiosos — no pocos — haciendo méritos y sometiéndose a todo, en espera de prebendas episcopales y otros. ${ }^{68}$

\section{Ante la violencia subversiva}

Las reuniones pastorales se convirtieron, en buena medida, en reuniones dominadas por una agenda política y sociológica. Se afirmaba que las ciencias sociales usaban el método marxista como instrumento para comprender mejor el Evangelio en la realidad de pobreza. Aunque se rechazaba la síntesis de marxismo y cristianismo, se planteaba la lucha de clases como hecho concreto y como método. ${ }^{69}$ En recurrentes asambleas prelaturales, la reflexión giró en torno a la Teología de la Liberación, con conferencias dictadas por el propio padre Gustavo Gutiérrez, quien subrayaba la distinción entre ortodoxia y ortopraxis. ${ }^{70} \mathrm{El}$

68. Actas de la asamblea de la prelatura de Ayaviri (1986), folios146-148.

69. Actas de la asamblea de la prelatura de Ayaviri (1984), folio 79.

70. Actas de la asamblea de la prelatura de Ayaviri (11 de noviembre de 1983), folio 59 . 
padre Álvarez ${ }^{71}$ consideraba un avance positivo el hecho de que «Roma» hubiera «exigido a la Iglesia peruana que se defina respecto de la Teología de la Liberación» porque esta «creciente polarización» era una constatación de cómo «la fuerza histórica de los pobres ha llegado hasta la cumbre de la Iglesia, como un cuestionamiento a la Iglesia universal». Y añadía, a modo de arenga, que «este debate es un tiempo de prueba para los que han optado por los pobres que deben enfrentar el reto de ahondar el mensaje y radicalizar el compromiso».

Estos planteamientos fueron la base teórica que permitió que en las reuniones pastorales se terminaran asumiendo medidas como formar una Comisión Pastoral de la Tierra y apoyar las movilizaciones campesinas en contra de un liberalismo económico que había convertido la tierra en mercancía:

[...] conocer y hacer conocer el DS 009-91-ag. que propicia el retorno del latifundio, del liberalismo económico salvaje al campo, de la tierra = mercancía, oferta al capitalista y trabajada por el peón campesino. Levantar nuestra voz de protesta ante la política agraria; acción popular contra el DS 009, movilización campesina, regional [...] apoyar a las organizaciones campesinas como dice nuestro plan pastoral [...] Dar forma a la comisión pastoral de la tierra (CPT) de la prelatura, que tendrá por tarea informarse e informar a sectores de la Iglesia y productores campesinos

71. Actas de la asamblea de la prelatura de Ayaviri (15-19 de octubre de 1984), folios 77-78. 
sobre la problemática de la tierra y animar la pastoral agraria; podría participar en esta comisión unos responsables de la federación campesina, un representante de la ARPC, uno del IER, un responsable pastoral [...] bajo la dirección del Obispo. ${ }^{72}$

Cuando el estallido de la subversión senderista llegó al sur andino, alrededor del año 1982, durante la administración de monseñor Francisco d'Alteroche, ${ }^{73}$ el prelado insistía a sus agentes pastorales, religiosos y sacerdotes que se preocuparan más por los temas sociales y políticos. Le llamaba la atención el hecho de que «los sacerdotes y religiosos están muy al tanto de los Sacramentos pero con cierta distancia de los temas sociales», y ante ello se preguntaba si veían o no «la gravedad de los problemas sociales». ${ }^{74}$ Estas prioridades pastorales trajeron como consecuencia una excesiva participación en actividades políticas, al punto de que surgieron comentarios que identificaban la acción pastoral con la subversión senderista. Esta impresión, que dañaba la imagen de la Iglesia en Ayaviri, suscitó una respuesta del propio monseñor d'Alteroche:

[...] la prelatura y sus agentes pastorales se han visto comprometidos con los pobres y han sufrido ataques y calumnias. Hay clima de odio y muerte en Melgar y Carabaya. Ha habido conversaciones con el Episcopado, ministro y

72. Actas de la reunión pastoral zonal de la zona de Carabaya en Ajoyani (1991).

73. Monseñor Francisco d'Alteroche administrará la prelatura de Ayaviri entre los años 1982 y 1991.

74. Informe de la reunión zonal en Ayaviri el 19 de noviembre de 1984. 
presidente. [...] Hay extremistas que se representan como de Iglesia $[. .$.$] Cada día se ven menos recursos para el Sur$ Andino y la situación se torna más propicia para la violencia. Cuidar lo que escribimos y escriben los animadores en estos cursos. Mejor darles un resumen final, completo. Preocuparnos por los problemas detonantes de violencia en nuestros sectores, así como de las agrupaciones humanas más infiltrables por violentistas. ${ }^{75}$

En realidad, lo que el prelado evidenciaba era una abrupta toma de conciencia de que muchas veces había «semejanzas entre las palabras de los agentes pastorales y los violentistas, y eso confundía a los que los escuchaban». ${ }^{76}$ Ante esta constatación, se pidió en asamblea cuidar el lenguaje y que la carta del prelado fuera más concientizadora que condenatoria para quienes acusan de violentistas a los agentes pastorales.

\section{Político-democratizadora (1993-2005)}

Los años noventa significaron una profunda transformación del Perú. Contreras y Cueto (2007) afirman que «esa década vino a cerrar el ciclo abierto con los golpes militares de los años sesenta, que dieron paso al estado desarrollista», y que las trasformaciones ocurridas durante esa década alinearon al Perú dentro de «la revo-

75. Actas de la reunión zonal de Sandia realizada el 11 y 12 de abril de 1986. Ese año coincide con la fundación de la Vicaría de la Solidaridad, el 4 de julio de 1986.

76. Actas de la reunión zonal de Sandia del 13 y 14 de junio de 1986. 
lución conservadora» que se propuso acabar con el paradigma del Estado redistributivo y asignarle a la economía de mercado el rol principal en la organización de las relaciones sociales.

Esta década estuvo marcada por el largo gobierno autoritario de Alberto Fujimori, que se abocó a una profunda reorganización del Estado, con un plan económico ortodoxo que logró ordenar la política fiscal, reducir la inflación, estabilizar la moneda y reinsertar al país en el sistema financiero internacional. En este contexto general, un momento importante, poco después del autogolpe de 1992, fue la captura de Abimael Guzmán, el fundador y máximo líder de Sendero Luminoso. Este fue un golpe certero para acabar con este grupo terrorista. Luego vino el Acuerdo de Paz firmado por los líderes senderistas, las deserciones propiciadas por la Ley de Arrepentimiento, la labor de las rondas campesinas y el rechazo masivo a la violencia; todo ello fue diezmando rápidamente a esta organización subversiva.

En cuanto a la lucha contra Sendero Luminoso en el sur andino, recordemos que como parte de la contraofensiva policial y militar que desplegó el Estado, entre 1991 y 1992 se decretó el estado de emergencia en casi todas las provincias del norte de Puno: Azángaro, Carabaya, Huancané, Melgar y Sandia. En Azángaro y Melgar se lograron conformar comités de autodefensa que comenzaron a enfrentarse contra Sendero. Se establecieron bases militares y se realizó un efectivo trabajo de inteligencia.

Por otro lado, hacia el año 1993, el departamento de Puno registraba los siguientes indicadores demográficos: contaba con una población de 1079849 habitantes, con un 4,8\% de crecimiento anual poblacional. Presentaba la proporción nacional más alta 
de vida rural, porque el $60,8 \%$ de sus habitantes vivían en el campo. Esto explica también el porqué en ese momento el analfabetismo afectaba al 22,2\% de la población.

Otra situación que se debe considerar es que después de la captura de Abimael Guzmán Reynoso, la Iglesia también participó en el proceso de pacificación. En algunos lugares, los terroristas arrepentidos primero se entregaban en las parroquias u otras dependencias de la Iglesia, para después entregarse a las Fuerzas Armadas (Klaiber 1997: 277). Sin embargo, Klaiber considera que «la labor más importante que prestó la Iglesia fue más bien su atención a los presos falsamente acusados de terrorismo y la ayuda que ofrecía a sus familiares».

\section{Incluyendo la exclusión}

Con la derrota del terrorismo y la atenuación de la violencia, el discurso de defensa de los derechos humanos migró hacia la reivindicación de los grupos excluidos — ya no solo campesinos e indígenas, sino también mujeres-, la defensa del medioambiente, la construcción de una teología indígena, etcétera. Además, el Informe final de la CVR se convirtió en documento medular del trabajo pastoral surandino. Gustavo Gutiérrez y la Teología de la Liberación continuaron siendo la «materia prima» de la lectura de la realidad económica y sociopolítica, y también del plan pastoral: el pueblo pobre y su cultura. Así lo reconoció el padre Fritsch ${ }^{77}$ ante monseñor Juan Godayol Colom, ${ }^{78}$ afirmando que sin una organización

77. Actas de la asamblea de la prelatura de Ayaviri (2002).

78. Obispo prelado de Ayaviri entre los años 1992 y 2006. 
autónoma del pueblo, no se lograría la liberación del pueblo de Dios. Y además, se hizo hincapié en que la evangelización es inculturación y liberación.

Se puede afirmar que gran parte de la actividad pastoral de la prelatura continuó estando marcada por preocupaciones y presupuestos políticos, económicos y sociológicos, al punto de que se llegó a incorporar explícitamente el «espíritu del Informe Final y las Recomendaciones de la Comisión de la Verdad y Reconciliación (CVR)» como el «el eje vertebrador» ${ }^{79}$ de las acciones institucionales.

De la misma manera, desde el Instituto de Pastoral Andina se promovió explícitamente "programas de formación política» para el «fortalecimiento de la sociedad civil», lo que se realizó a solicitud de la agencia donante Misereor. ${ }^{80}$ La coordinación de la pastoral y coordinación de las mujeres buscó impulsar «activamente la participación política y mayor participación eclesial que asegure menos marginación y racismo». ${ }^{81}$ Sus ejes de formación fueron siempre la opción por los pobres y los binomios fe y política, fe y cultura, y fe y vida. En cuanto al proceso de formación para el cambio, se desarrollaron «temas sobre la per-

79. Informe de las actividades institucionales en el año 2005. En este informe, se hará evidente la escasa preocupación por la vida sacramental y catequética. No se hace referencia a bautismos ni confirmaciones. Un dato revelador de tal situación se muestra en la última parte del informe, que revela que la pastoral familiar apenas cuenta con cuatro parejas en tres parroquias para ese año.

80. Informe de las actividades institucionales en el año 2005.

81. Informe de las actividades institucionales en el año 2005. 
sona (autoestima, afectividad, sexualidad, relaciones propias de género)», ${ }^{82}$ sobre la «identidad cultural eclesial», y sobre la «realidad nacional y regional».

Respecto a la coordinación de jóvenes, se realizó una clara distinción entre dos tipos de grupos juveniles: los grupos eclesiocéntricos y los grupos sociopolíticos. Estos últimos fueron evaluados muy positivamente, llegándose a señalar que «por consenso, queremos promover una formación que lleve a los jóvenes al compromiso social y político desde una experiencia de identificación cristiana-eclesial» ${ }^{83} \mathrm{y}$ desde la propia identidad cultural.

En cuanto a la pastoral del campo, se propuso una labor catequética centrada en tres ejes: inserción social y política, valores como la responsabilidad, y la solidaridad e identidad cultural. De la misma manera, se realizó una interpretación conflictiva de la cultura peruana y se rechazó el aporte cultural occidental. Sobre el área de la pastoral social, se promovió la identificación de la vocación de la Iglesia en el mundo desde una perspectiva social, en la cual esta es considerada «una actora social para animar una movilización social hacia nuevas relaciones interpersonales, socioeconómicas, culturales, políticas y eclesiales». ${ }^{84}$

También se planteó la constitución del Taller de Líderes para el Fortalecimiento de la Sociedad Civil con tres ejes temáticos:

82. Informe de las actividades institucionales en el año 2005.

83. Informe de las actividades institucionales en el año 2005.

84. Informe de las actividades institucionales en el año 2005. 
primero, la persona desde una perspectiva basada en el mensaje de la CVR, que busque combatir la exclusión y el racismo; segundo, la identidad cristiana-eclesial; y tercero, el rol social de la Iglesia. ${ }^{85}$ En este punto, hay que aclarar que cuando se hablaba de «reconciliación» no se lo hacía en un sentido evangélico, pues estuvo muy presente una decodificación sumamente conflictiva de la realidad.

En esta misma línea de trabajo, los equipos sociales de la prelatura se abocaron a fortalecer a la sociedad civil para el desarrollo de sus pueblos siguiendo un enfoque eminentemente político. Así, tenemos que las actividades del IER, Cáritas, la Oficina Diocesana de Educación Católica (ODEC), la Coordinación de Movimientos Laicos Cristianos (ComLAC), Comunicación Social, la Granja Don Bosco y la Vicaría de la Solidaridad (VS) presentaron como ejes de trabajo la lucha contra la violencia, el fortalecimiento de la institucionalidad democrática, el fortalecimiento de las organizaciones campesinas -incluyendo las rondas campesinas y la justicia comunitaria - y el impulso de la revista Runa. ${ }^{86}$ Por otro lado, los animadores cristianos y de coordinación pastoral de mujeres trabajaron persiguiendo los siguientes objetivos: «a. Motivar a los animadores cristianos y organizaciones de mujeres para que se siga valorando su sabiduría Andina Cristiana [y] b. Motivar, fortalecer la Iglesia ecuménica con comunidades cristianas desde las comunidades eclesiales de base». ${ }^{87}$

85. Informe de las actividades institucionales en el año 2005.

86. Informe de las actividades institucionales en el año 2005.

87. Informe de las actividades institucionales en el año 2005. 


\section{El afán democratizador}

La preocupación por la «democratización» de la Iglesia va a ser el centro de la reflexión eclesial durante los períodos políticoliberacionista y político-democratizador. Ya en 1986, monseñor d'Alteroche insistía en este tema porque —en sus palabras«la democracia en la Iglesia es parte de la liberación del pueblo». ${ }^{8}$ Dieciséis años después, monseñor Godayol afirmaba que «uno de los valores principales del Sur Andino y de nuestra prelatura es que vamos avanzando en este aspecto más democrático, participativo, donde se tiene en cuenta a los consultores».

Ha sido esta una iglesia democrática «a lo nuestro» y esto es un valor porque se ve en otras instancias. Aquí el obispo no manda y los demás a obedecer y a callar, cosas que son completamente equivocadas y retrógradas, fuera de contexto. Hoy día eso ya no se admite tanto. Es así que en Europa ha comenzado la revolución. Como se mantiene un sistema muy cercano al europeo, resulta que hay parroquias, hay sacerdotes, hay obispos que dicen: ya se acabó, nosotros tenemos que sintonizarnos con el pueblo que nos toca servir. Ya han roto esquemas de cierta manera, la gente ha entrado en rebeldía para escuchar la voz del espíritu. Porque a veces las voces de los escribanos detrás de escritorios lujosos que no ven la pastoral en el campo pues no entienden. Así que yo creo que es uno de los aspectos que tenemos que seguir trabajando porque yo también cuando

88. Actas de la reunión zonal de Ayaviri (1986). 
viajo por la prelatura veo parroquias democráticas y otras muy imperialistas, muy gamonales donde el encargado de la parroquia se atribuye más de lo que le corresponde. ${ }^{89}$

La reflexión sobre este tema llevó incluso a la distinción de diferentes niveles de fortalecimiento de la democracia, ${ }^{90}$ que comenzaban por el nivel personal — la autocrítica - y continuaban por el institucional — parroquia, consejo pastoral, comunidad cristiana y transparencia en lo económico, etcétera- El padre Fritsch narraba que cuando en el pueblo de Antauta denunció al alcalde por corrupción llamándolo «dictador de la democracia», ${ }^{91}$ bajo su auspicio el pueblo creó una comisión revisora de cuentas y juntas vecinales, y promovió asambleas populares y denuncias a la Fiscalía. Según el sacerdote, todo esto se logró gracias a «la Iglesia, especialmente por intermedio de la Mesa de Concertación». ${ }^{92}$ Pero la reflexión del padre Fritsch pretende ir un poco más lejos y así establecer, en sus propias palabras, «la relación entre la democracia del pueblo y la Iglesia»:

[...] si en la parroquia no tenemos mecanismos de democracia, de consejos pastorales, comunidad cristiana, si no hay mecanismos de rendición de cuentas de la gestión parroquial, no tenemos ninguna autoridad moral para luchar por la democracia en el municipio. Por eso, yo veo la relación en la medida que tratamos de avanzar, mecanismos

89. Actas de la asamblea de la prelatura de Ayaviri (2002), p. 36.

90. Actas de la asamblea de la prelatura de Ayaviri (2002).

91. Actas de la asamblea de la prelatura de Ayaviri (2002), p. 39.

92. Actas de la asamblea de la prelatura de Ayaviri (2002), p. 39. 
de democracia y transparencia económica en la Iglesia, en esa medida podemos construir la democracia del pueblo. ${ }^{93}$

No obstante la intención democratizadora, era innegable que este espíritu pluralista tal vez había resquebrajado ciertas convicciones de los tiempos iniciales. «Muchas veces, hemos hablado tan solamente del mismo tema de la Realidad Nacional SocioPolítica y Económica a veces sin tomar en cuenta la palabra de Dios y sin dar una solución fija a lo que debatimos». ${ }^{94} \mathrm{Al}$ parecer, en algunos momentos no había consenso absoluto sobre el enfoque teológico que debía animar las actividades pastorales de toda la prelatura. Uno de los delegados surandinos recomendaba tener «mucho en cuenta» los temas que se van a tratar, como punto de partida, ya que «el tema debe ser a partir de la palabra de Dios, conocer bien lo que es Dios de la vida», y a través de esta palabra de Dios «tenemos que ver nuestra situación». ${ }^{95}$

Otro aspecto de particular preocupación llegó a ser todo lo referente a la liturgia y la inculturación. Monseñor Juan Godayol sostenía que «en el sur andino no han avanzado más en las expresiones litúrgicas propias e inculturadas de esta zona, así como se ha avanzado en el África [porque] tal vez no hemos comprendido bien la liturgia $[\mathrm{y}$ ] tenemos miedo de entrar en nuevas formas e inculturadas». ${ }^{96}$ Ante ello y como respuesta, propuso «rescatar esa comisión o ese sector de la liturgia inculturada de la prelatura».

93. Actas de la asamblea de la prelatura de Ayaviri (2002), p. 39.

94. Actas de la reunión zonal de Melgar-Ñunoa (1989).

95. Actas de la reunión zonal de Melgar-Ñuñoa (1989).

96. Actas de la asamblea de la prelatura de Ayaviri (2002), p. 40. 
El padre Fritsch era más bien de la opinión de «imitar un poco» la experiencia brasileña de las comunidades eclesiales de base (CEB), a las que consideraba «la fuerza de la Iglesia brasilera». ${ }^{97}$ En esa misma asamblea se hicieron presentes algunas voces de disidencia cuando el padre Gabriel lanzó una crítica contra la Teología de la Liberación por el perjuicio que ha causado a la inculturación de la liturgia, y calificó a esta teología de estar «muy orientada a la transformación de las cosas, donde las cosas valían en función de la transformación, de la renovación y eso nos ha hecho descuidar toda la parte espiritual que en unos casos se ha visto o bien como mágica o bien como dinámica. Entonces hemos confundido el ritualismo con la espiritualidad». Consideraba que «este descuido frente a lo simbólico que encierra la liturgia [era un] descuido frente a la fiesta misma. Finalmente, no sólo es una cuestión de actitud incultural, en el sentido de que el pueblo se debe a sus modos, a sus reglas [...] no se trata sólo de módulos andinos sino también de adecuar con esto la forma de celebración de otras culturas en un mundo como el nuestro, puede ser más bien enriquecedoras». ${ }^{98}$

\section{REFERENCIAS}

Fuentes primarias (ordenadas cronológicamente)

- Decretos de la prelatura de Ayaviri (1958-1974)

- Anales de la prelatura de Ayaviri (1959-1974)

97. Actas de la asamblea de la prelatura de Ayaviri (2002), p. 41-42.

98. Actas de la asamblea de la Prelatura de Ayaviri (2002), p. 42. 
- Actas del Consejo Presbiteral de la prelatura de Ayaviri (30 de noviembre al 3 de diciembre de 1976)

- Actas del plan pastoral de la prelatura de Ayaviri (18 al 22 de abril de 1977)

- Actas de la asamblea de la prelatura de Ayaviri (1979-1985)

- Actas de la reunión zonal de Melgar (20 de diciembre de 1984 en Ayaviri)

- Informe de la reunión zonal en Ayaviri (19 de noviembre de 1984)

- Actas de la asamblea de la prelatura de Ayaviri (1986)

- Actas de la reunión zonal de Sandia (11 y 12 de abril de 1986)

- Actas de la reunión zonal de Sandia (13 y 14 de junio de 1986)

- Actas de la reunión zonal de Ayaviri (1986)

- Actas de la asamblea de la prelatura de Ayaviri (1987)

- Acta de la reunión zonal de Sandia (24 y 25 de abril de 1987)

- Actas de la reunión ampliada de la delegación. AC: I de jóvenes, I de mujeres de cada parroquia (1987)

- Actas de la asamblea de la prelatura de Ayaviri (1988)

- Actas de la asamblea de la prelatura de Ayaviri (1989)

- Actas de la reunión zonal de Sandia (23 al 30 de abril de 1989)

- Actas de la reunión zonal de Melgar-Ñuñoa (1989)

- Actas de la reunión zonal de la provincia de Carabaya, Macusani (1-2 de diciembre de 1987)

- Actas de la asamblea de la prelatura de Ayaviri (19 de octubre de 1990)

- Actas de la asamblea de la prelatura de Ayaviri (1991)

- Actas de la reunión pastoral zonal de la zona de Carabaya en Ajoyani (1991)

- Actas de la asamblea de la prelatura de Ayaviri (19 de octubre de 1992)

- Actas de la asamblea de la prelatura de Ayaviri (2002)

- Informe de las actividades institucionales en el año 2005 


\section{Fuentes secundarias}

Apaza Quispe, Hugo

2001 Temas históricos de Juliaca. Compendio histórico cultural. Juliaca: edición del autor.

Camprendon, Gabriel

1992 Luis Dalle: un hombre libre. Lima: Tarea.

Comisión de la Verdad y Reconciliación (CVR)

2003 Informe final. Disponible en <http://www.cverdad.org.pe/ ifinal/index.php>.

Contreras, Carlos y Marcos Cueto

2007 Historia del Perú contemporáneo. Desde las luchas por la independencia hasta el presente. Lima: Instituto de Estudios Peruanos.

DALLE, Luis

1969 «El despacho». Allpanchis 1, Cusco, Instituto de Pastoral Andina, pp. 139-154.

Dodson, Jimmie

1980 «Prophetic Politics and Political Theory in Latin America», Polity, vol. XII, n. ${ }^{\circ}$, Spring, pp. 388-408.

GonZÁLEZ, José Luis

1982 «Una experiencia eclesial: el sur andino». En: Tovar 1982, pp. 11-27. 
KLAIBER, Jeffrey

1997

Iglesia, dictaduras y democracia en América Latina. Lima: Fondo Editorial de la Pontificia Universidad Católica del Perú.

1988

La Iglesia en el Perú. Lima: Fondo Editorial de la Pontificia Universidad Católica del Perú.

KLARÉN, Peter

$2004 \quad$ Nación y sociedad en la bistoria del Perú. Lima: Instituto de Estudios Peruanos.

Lozano, Arminda y Emilio Mitre

1987 Análisis y comentarios de textos históricos. I. La Edad Antigua y Media, Madrid: Alhambra.

Macaulay, Michael

1972 Ideological change and internal cleavages in the Peruvian Church: change, status quo and the priest; the case of ONIS. Tesis Ph. D., University of Notre Dame.

McClintock, Cynthia

1998 Revolutionary Movements in Latin America: El Salvador's FMLN and Peru's Shining Path. Washington, D. C.: Institute of Peace Press.

1989 «Peru’s Sendero Luminoso Rebellion». In Susan Eckstein (ed.), Power and Popular Protest. Berkeley: University of California Press, pp. 61-101.

Masterson, Daniel

Militarism and politics in Latin America: Peru from Sánchez Cerro to Sendero Luminoso. Westport, Connecticut: Greenwood Publishing Group. 
PÁsARA, Luis

1986

Radicalización y conflicto en la Iglesia peruana. Lima: Ediciones El Virrey.

REGAN, Jaime 1971

«Reflexión pastoral sobre los ritos indígenas». Allpanchis 3, Cusco, Instituto de Pastoral Andina, pp. 202-212.

RoBB, Carol

1978

Integratios of Marxist constructs into the Theology of Liberation from Latin America, Tesis Ph. D., Boston University Graduate School.

Romero, Catalina

1982 «Cambios en la relación Iglesia-sociedad en el Perú: 1958-1978». Debates en Sociología, n. ${ }^{\circ}$ 7, Lima, pp. 115-141.

SMITH, Brian H.

1982

The Church and Politics in Chile. Princeton: Princeton University Press.

Tovar, Cecilia

1982 Dos obispos del sur andino, Luis Vallejos, Luis Dalle: en el corazón del pueblo. Introducción de José Luis González: Lima, Centro de Estudios y Publicaciones (CEP).

Tovar, Cecilia (ed.)

2006 Ser Iglesia en tiempos de violencia. Lima: Centro de Estudios y Publicaciones (CEP). 


\section{WeBB, Richard}

1977 «Government Policy and the Distribution of Income in Peru, 1963-1973». Harvard Economic Studies, n. ${ }^{\circ}$ 47. Cambridge, Massachusetts \& London, England: Harvard University Press. 
